\title{
Impact of Parental Migration on Children's Education and Protection: Evidence from Sri Lanka
}

\section{Priyanga Dunusingha}

\section{Abstract}

International labour migration has been one of the key sources of employment generation and foreign exchange earnings for Sri Lanka since the early 1980s. A sizable share of the total migrants falls into the 25-44 agegroup and their migration may have implications on education and protection of children left behind. This study aimed at examining the impact of parental migration on education and protection of children left behind by employing a mixed method of data analysis. This study collected quantitative data by administering questionnaire survey for a sample of randomly selected households. Key informant interviews and in-depth interviews were conducted to collect qualitative data. Both descriptive and regression analyses were employed in data analysis and the results obtained from above techniques were further enriched by in-cooperating insights from key informant interviews and in-depth interviews. Insights from the descriptive analysis, key informant interviews, and in-depth interviews highlighted some suggestive evidence that children in migrant households face difficulties with their school attendance and performance compared to children in non-migrant households. Our regression results failed to support above evidence that migration, in general, has an effect on educational achievement. Nevertheless, we found strong statistical evidence to suggest that educational performance is lower among the children whose mother has migrated. In other words, probability is high that children in mother migrant households perform poorly at test conducted at school-level. Similarly, it was found that left-behind children's protection is under severe risks in mother migrant households where father and close relatives are relatively weak in capacities. In contrast, in father migrant households, adult children are under greater protection provided mother and close relatives are with higher capacities. Mothers involve through a number of ways to improve children's educational achievement and protection, and her absence at home exposes children to a greater physical and physiological risks.

Keywords: Children Left-behind, Education, Labour Migration, Logit Model, Sri Lanka
${ }^{1}$ Department of Economics, University of Colombo, Sri Lanka

pmdunu@yahooo.com 


\section{INTRODUCTION}

Migration can be defined as movement of people from their roots to other locations, whether inside or outside the country. Migration, regardless of inside or outside a territory, has multiple consequences. Moreover, among others things, it can have a significant impact on a country's economy, politics, and environment. There can be a number of positive and negative consequences associated with migration, some felt at household level whereas the rest at individual. Since early days, human migration has been caused by factors such as poverty, low wages, and unemployment as well as political factors such as security concerns and conflicts. At present, migration has become a global phenomenon and it has been driven by the functioning of the global capital market, with global trade in goods and services, flow of investment, and the quality of life in different parts of the world. Over the last few decades, the pace of international migration has increased considerably. Moreover, international migration has played a key role in shaping and reshaping the demographic features of countries and determining the pace of their economic growth and development. According to (United Nations Department of Economic and Social Affairs (2019) the number of international migrants reached at 272 million in 2018,

\footnotetext{
${ }^{1}$ In 2014, government of Sri Lanka makes it compulsory to submit a family background report when a married female intend to migrate for work.
}

representing about 3 per cent of the world's population. Between 2000 and 2018, the number of migrants originating from middle-income countries increased faster than those from the other income categories.

In Sri Lanka, during the last few decades, the number of migrants increased rapidly due to both demand and supply factors. In 2018, around 1.5 million Sri Lankan migrated for various purposes and one out of every seven migrants seeks employment opportunities. In Sri Lanka, the share of the females in total labour migration has remained relatively higher than that of the male until around 2009. For instance, female migrants accounted for 73 per cent in 1995 and this share, though declined over the years, continues to remain high (50 per cent in 2018) to this date. Several factors such as general improvement in economic conditions, changes in government policy on female labour migration, and higher demand for Sri Lanka's male workers in abroad resulted in an increase of the share of male in total out-migration $^{1}$. Around 55 per cent of total female migrants fall into the age category of 25-44, the childbearing age group. Similarly, around 65 per cent of total male migrant fall into the age group of 25-44. These imply that a sizable number of migrants are parents and they left behind kids when migrating for work. In most cases, 
parental migration often brings higher income and hence potentially more economic resources for children's education and health investment. Nevertheless, lack of parental care may have adverse effects on education and protection of left-behind children. The net effect of parental migration depends on the relative magnitude of the two effects and it is largely an empirical issue.

In the context of developing countries, it is imperative to identify the effect of parental migration on children' education and protection, partly due to the fact that many developing countries have identified international labour migration as one of the major avenue of reducing domestic unemployment and enhancing the living standards of general masses and any negative effects may lead to a vicious cycle. In particular, low human capital formation among left-behind kids could lead to another round of labour migration thereby perpetuating the society as a whole. Moreover, factors such as demographic transition - from extensive family structure to intensive family structure-, absence of a public funded well-functioning child protection system, wide-spread crime involving children, and an increasing individual-centric social formation may increase the vulnerability towards low human capital formation among left-behind kids.

The main objective of this study is to examine the impact of parental migration on children's education and protection. Specifically, this study attempts to (a) examine how the living environment experienced by a child in a migrant household differs from that of in the non-migrant household (b) evaluate the impact of parental migration on children's school performance and protection, and (c) evaluate whether the impact differs on the basis of who migrate for work.

The section two discusses both theoretical and empirical literature on the impact of parental migration of educational performance and protection of children left behind while a discussion on methodology is presented in section three. Section four presents and discusses results derived from both descriptive and regression analyses while the last section makes some concluding remarks.

\section{LITERATURE SURVEY}

United Nations Convention on Rights of the Child adopted in 1989 defines a 'child' as a person below the age of 18 . It was ratified by many countries including Sri Lanka, to protect children from economic and sexual exploitation, violence, and other forms of abuse and to enhance the rights of children to education, health care, and a decent standard of living. These rights could be grouped into four categories namely; survival rights, development rights, protection rights, and participation rights. The study adopts the right based approach in examining the effect of parental migration on children's 
education, one of the pivotal rights. According to theoretical insights in Sociology, Anthropology, and Phycology, the family (the household) plays a key role in guaranteeing child rights that come under the above four sub-categories. Incentives, in various forms such as instructions, rewards, care, love, kindness, and punishments, given by family members shape the personality and the development. The absence of parent (either one or both) may create a vacuum at household level thereby leading to befall some social negatives. A number of sociological perspectives (theories) guide the present study. Those theoretical models aim at explaining theoretical underpinning related to the questions such as what do children learn and how do they learn? When do children develop their emotional capabilities similar to that of the adults? How do children process information? How do experiences accumulated during the childhood affect personality development?

The functionalist view of socialization theory pronounces socialization as older generations pass culture on to younger generation (Mackie, 2002). This model assumes that child is passive, children must be shaped to fit in, and cultural transmission protects survival. In this respect, parents play a key role in molding children who fit well onto existing socio-economic, political and cultural set up. Social learning perspective, developed by Vygotsky (2004) argues children interpret, organize, and use information from their environment. Each family provides a useful environment at the early age of any child in social learning where they learn basics which make the foundation for greater association with the rest of the society. This model assumes that child development occurs in discrete stages and child must accomplish one stage successfully before moving onto the next. Parental migration may affect the social learning of children left behind due to improper family environment and as a results violation of child rights could take place.

The interactionist perspective, developed by George and Edwards (1989) argues that children develop identity in response to interaction with others. This approach assumes that child is an active agent and identity is based on children's perceptions of others' perceptions of them. Absence of parents due to migration may affect children through losing interaction with closest ones thereby affecting the rights. The interpretive reproduction perspective, modeled by Corsaro (1997), argues that children negotiate, share and create culture with adults and each other. One of the important assumptions of this perspective is that children influence adults in addition to being influenced by them. Hence, parental interaction is essential in shaping the childhood and protecting child rights. The ecological perspective, developed by Bronfenbrenner (1986), maintains child develops competence 
within a social network. On this respect, family in collaboration with schools makes an important contribution to protect child rights. The critical perspectives, developed by Thorne (1987) and James, et. al. (1998) argues children resist domination both actively and passively. This model assumes children are active agents and adults have more power than children and use it to control and dominate them. Moreover, it is assumed that like any other oppressed groups, children will fight back domination. Thus, interaction with adults (mainly parents) molds the child and maintains child rights.

In addition, psychological theory of behaviorism emphasizes the role of reward and punishment play in children' learning process (Delprato and Midgley, 2002). This theory assumes the child is passive and adults could shape the children. It could be assumed that children in parentmigrant families may receive such reward and punishment at sub-optimal level thereby affecting their rights. Theoretical perspectives mentioned above shed light on the relationship between the family and childhood where family in general and in particular parents play a critical role in shaping the behavior and they are instruments in guaranteeing child rights including rights to education. The existing literature indicates various channels through which parental migration could influence the human capital development of children left- behind (Dustman and Glitz, 2011). On the one hand, an increase in income, through migration and remittance, could ease the household budget constraint and thereby increase household spending on education resulting in reduction of child labor. A number of empirical studies have supported above this theoretical (Cox Edward and Ureta, 2003; Adams and Cuecuecha, 2013; Alcaraz, Chiquiar, and Salcedo, 2012; Yang, 2008). Absence of parents at home could have negative effects on children left-behind through a number of channels. These include loss of local earnings, the lack of parenting inputs for educational activities, and the psychological cost associated with family separation. Moreover, parental migration also increases the migration prospects of children. Such influence can induce more or less educational investment in children depending on the difference in the rates of return to human capital between the migration destination and the place of origin.

Recently, there has been a growing empirical literature that examines the effects of parental migration on educational performance of children left-behind where focus was mainly on the dimensions of time allocations and schooling attainment. Antman (2013), for example, finds that a Mexican father's migration to the U.S. decreases study hours and increases work hours for children left-behind. Chang, Dong, and Macphail (2011) employed the Sri Lanka Health and Nutrition Survey 
(CHNS) to examine the time allocations of left-behind children, and found that children of migrant households spend more time in household work. Nevertheless, findings on children's schooling attainment are mixed (McKenzie and Rapoport, 2011).

A number of previous studies have looked into the effect of parental migration on human capital formation in the context of Sri Lanka (Hettige, 1999; Gumbard, 2008; Jampaklay, 2006; Lakshman, Perera and Sangasumana, 2015; Perera and Jampaklay, 2014). The authors examine the effect of parental migration on various components of human capital formation, namely on educational performance and/or health related aspects such as nutrition. The findings of these studies are inconclusive. Therefore, the sign and the size of the overall effect of parental migration on the education and protection of children left-behind is unclear a priori and remains an empirical question. In the context of Sri Lanka, as far the author knows, none of the studies examine the educational performance and protection of leftbehind children in comparative sense, namely comparing against a comparable group of students from non-migrant families.

\section{DATA AND METHODOLOGY}

This study collects both qualitative and quantitative primary data from a

\footnotetext{
${ }^{2}$ A migrant household is a one that has at least one or both parents are in abroad for work at the time of
}

sample of households which contains both migrant households as well as non-migrant households ${ }^{2}$. First, taking into account the district-level migration flow and ethnic concentration, three administrative districts were selected out of the 25 districts in the country. Second, from each selected district, the Divisional Secretarial (DS) division reporting the highest migrant flow in 2018 was selected for the study. Third, five Grama Niladhari (GN) divisions were selected randomly from each selected DS division. Finally, the household questionnaire was administered to 150 migrant and 50 non-migrant households, selected randomly from $5 \mathrm{GN}$ divisions selected from each DS division. Accordingly, the household questionnaire survey was conducted covering 450 migrant households and 150 non-migrant households in the selected districts. Electoral lists maintained at GN level and the lists containing migrant household information at divisional secretariat office were utilized in drawing households for the sample. In addition, in-depth interviews were conducted with selected children (25 in each district) in migrant households and key public officials such as school principals, teachers, officers responsible for migrants at divisional secretariat office, and Divisional Secretaries. A special attention was given to the heterogeneity that exists among left-behind children when selecting individuals for the in-depth

the survey and current period of migration started six months prior to the survey was conducted. 
interviews.

A number of information areas were covered by the household survey; namely, demography, socio-economic background, family background, school attendance, homework engagement, children's perceptions, attending to tuition, school performance, and school dropouts. In addition, data on living environment, changes into living environment, children's feeling towards themselves, and social perceptions towards leftbehind children were also collected. The study interviewed children (between 10-18 years) in both migrant and non-migrant households.

This study aims at employing both descriptive and regression analyses in examining the impact of parental migration on educational performance and protection of children left-behind. Insights of key informant interviews and in-depth interviews will be blended along with the findings from the above analyses. Following Logit model was employed in investigating the impact of parental migration on educational performance;

$y_{i}=X \beta+Z \gamma+\alpha D+u_{i}$
In the equation (1), yi denotes our dependent variable that takes 1 if a student ranks his/her educational performance as 'average or above average' and otherwise zero (if a student ranks his/her educational performance as 'below the average' $)^{3}$. Matric $X$ includes variables representing students' after school engagements, family background, and school quality while $\mathrm{Z}$ contains variables related to migration status. Matrix D contains district dummy variables and ui is the usual error term. $\beta, \gamma$, and $\alpha$ are parameter vectors.

\section{RESULTS AND DISCUSSION}

\section{Characteristics of Household Survey}

Table 1 reports data on age distribution of household members by migrant and non-migrant households in the sample. It is interesting to note that the share of relatively small children (less than 10 years) is higher in-migrant households than that in non-migrant households for all district except for Nuwara Eliya. Key informant discussions revealed that economic burden is one of the main factors that force household members to migrate even if they have to leave behind small kids. However, this pattern is not visible for other agegroups.

performance were offered to them as excellent, good, average, poor, and very poor. ${ }^{3}$ During the survey, students were asked to rank
their educational performance and five levels of 
Table 1: Age Distribution: Migrant Households Vs. Non-Migrant Household

\begin{tabular}{lrrrrrr}
\hline \multirow{2}{*}{ Age group } & \multicolumn{2}{c}{ Kurunegala } & \multicolumn{2}{c}{ Nuwara Eliya } & \multicolumn{2}{c}{ Batticaloa } \\
\cline { 2 - 7 } & $\begin{array}{c}\text { Non-Migration } \\
\text { HH }\end{array}$ & $\begin{array}{c}\text { Migration } \\
\text { HH }\end{array}$ & $\begin{array}{c}\text { Non- } \\
\text { Migration } \\
\text { HH }\end{array}$ & $\begin{array}{c}\text { Migration } \\
\text { HH }\end{array}$ & $\begin{array}{c}\text { Non- } \\
\text { Migration } \\
\text { HH }\end{array}$ & $\begin{array}{c}\text { Migration } \\
\text { HH }\end{array}$ \\
\hline$<=10$ & 10.0 & 14.3 & 19.5 & 16.4 & 10.8 & 17.8 \\
$11-20$ & 38.9 & 29.5 & 29.5 & 32.1 & 40.4 & 32.8 \\
$21-30$ & 2.8 & 7.6 & 6.3 & 7.5 & 6.3 & 9.8 \\
$31-40$ & 23.2 & 24.0 & 24.7 & 22.6 & 25.6 & 22.9 \\
$41-50$ & 19.9 & 14.7 & 9.5 & 14.6 & 11.7 & 10.4 \\
$51-60$ & 2.8 & 6.4 & 6.8 & 2.5 & 3.1 & 3.9 \\
$>=60$ & 2.4 & 3.5 & 3.7 & 4.2 & 2.2 & 2.4 \\
Total & 100.0 & 100.0 & 100.0 & 100.0 & 100.0 & 100.0 \\
\hline
\end{tabular}

Source: Based on household survey

According to our sample, in the Nuwara Eliya district, 'mothermigrated' households accounts for around 80 per cent of total migrant households in the district whereas this figure is around 34 per cent and 59 per cent in the Batticaloa and Kurunegala districts respectively (see Table 2). In contrast, share of 'father-migrated' households accounts for around half of the total migrant households in Batticaloa. The 'both-parents' migrated households are relatively high both in the Batticaloa and Nuwara Eliya districts.

Table 2: Sample Profile

\begin{tabular}{lrrrr}
\hline & Kurunegala & Nuwara Eliya & Batticaloa & Total \\
\hline Mother & 58.8 & 79.7 & 34.2 & 57.3 \\
Father & 35.3 & 18.9 & 52.0 & 35.6 \\
Both & 5.9 & 14.0 & 13.8 & 6.9 \\
\hline Total & 100.0 & 100.0 & 100.0 & 100.0 \\
\hline
\end{tabular}

Source: Based on household survey

Over 94 per cent of total migrants of our sample are in Middle East and around 60 per cent of them could be categorized as housemaids. Over 90 per cent of total female migrants (mothers) work as housemaids while 50 per cent of total male migrants (fathers) work as labourers. Among the both migrant households, over 70 per cent work as semi-skilled workers. These figures may reflect the level of freedom these migrated father and mother may enjoy in communicating with their children left behind at home. Moreover, in most cases, these migrants may visit the family once in two years. The majority 
of migrated fathers and mothers (over 70 per cent) have obtained less than secondary level of education while there are around 5-8 per cent of total migrated fathers and mothers who have not schooled at all. Migrated parents' low level of education could certainly have a negative impact on children education. Moreover, in terms of age, average age of migrated parents is 40 years while around 5-8 per cent of migrated parents are in mid 20s. Nearly 94 per cent of total migrants remit money to their households. Those that do not provide assistance are the ones who either migrated in recent months or migrated some years ago but do not keep regular contact, apparently disintegrated from the households. The survey found that fewer number of mothers as well as fathers keep less contact and do not send money or other assistance on regular basis due to limited association with the family members ${ }^{4}$. Similarly, it was revealed that some migrated mothers remit money to close relatives rather than the husband and household members do have less knowledge about the actual amount remitted by the mother. Yet, over 90 per cent of migrated mothers/fathers directly remit money to household members on monthly basis and the remitted money is mostly utilized for financing consumption expenditures such as food, cloth, education, health, and investing in

\footnotetext{
${ }^{4}$ In some cases, migrated mothers or fathers informed the family members about financial difficulties such as not receiving monthly wage as a reason for not remitting money to the household members.
}

improving housing conditions.

Children very often keep contacting with migrated parents in all districts. Among districts, percentage of children contacting migrated parents in the Nuwara Eliya district is relatively lower than that in both the Kurunegala and Batticaloa districts ${ }^{5}$. Telephone/internet phone has become the main mode of contact. In-depth interviews revealed that most children and migrated parent keep contact via Viber more frequently. More than half of the cases, except in the Batticaloa district, it is revealed that migrated parents and their household members contact each other every two to three days in a given week. Moreover, according to in-depth interviews, one session of communication lasts around 20-60 minutes. Most children have seen their migrated mother, father or both during the last 1 to 2 years while small percentage of children have not seen the migrated parent during the last three years. In Batticaloa, around 20 per cent of children among mother migrated households have not seen their mother during the last three years whereas in Nuwara Eliya this number remains around 10 per cent. Over 10 per cent of children among father migrated households have not seen their migrated father in all three districts. It reflects the fact that migrated fathers tend to stay somewhat

\footnotetext{
${ }^{5}$ It was found that in most households, migrated member as well as the members of the households do keep regular contact with each other.
} 
longer periods in abroad compared to migrated mothers. In contrary, children among both migrated households in Batticaloa have not seen their both migrated parents during the last two years. Around 10 per cent of children of all migrated households have not seen their migrated mother, father, or both during the last 3 years. This certainly may have implications on education provided those children do not receive sufficient care from the guardians.

\section{Parental Migration and Schooling}

More than 90 per cent of the interviewed children (both migrant and non-migrant households) are currently schooling. From the total sample of three districts, around 8 per cent of school-age children in nonmigrant households and 6 per cent of school-age children in migrant households do not school at present. Compared to the other two districts, a sizable number of school-going students in Batticaloa district do not school at present (see Table 3). For instance, 15 per cent of total nonmigrant household children and 9 per cent of migrant household children do not school at present in Batticaloa. It is reasonable to guess that 'war' related factors may have some influence on this situation ${ }^{6}$.

Table 3: School Attendance

\begin{tabular}{lrrrrrrrr}
\hline & \multicolumn{9}{c}{} & \multicolumn{2}{c}{ Nuwara } \\
& Kurunegala & \multicolumn{2}{c}{ Eliya } & & \multicolumn{2}{c}{ Batticaloa } & \multicolumn{2}{c}{ Total } \\
\hline & NM & M & NM & M & NM & M & NM & M \\
\hline Yes & 96.0 & 96.3 & 92.5 & 94.6 & 85.4 & 91.4 & 91.3 & 94.0 \\
No & 4.0 & 3.7 & 7.5 & 5.4 & 14.6 & 8.6 & 8.7 & 6.0 \\
\hline Total & 100.0 & 100.0 & 100.0 & 100.0 & 100.0 & 100.0 & 100.0 & 100.0 \\
\hline
\end{tabular}

NM: Non-Migrant; M=Migrant

Source: Based on household survey

A majority of school-going children attend to public schools in all three districts. In the Nuwara Eliya district, around 13 per cent of school-going children attend semi-government schools. As revealed during the indepth interviews, some mother migrants get their kids admitted to semi-government schools where hostel facilities are available so that kids receive better education and protection

\footnotetext{
${ }^{6}$ Batticaloa district was heavily affected by the civil war that lasted around 30 years. It is possible, that relatively low schooling may associate with
}

during their absence. Most of these schools are Christian or Catholic schools. A small percentage of children attend private school. In most cases, children attend schools located in nearby village or city. There is clear evidence that in Kurunegala and Nuwara Eliya, a higher percentage of schooling children in migrant households attend schools located in other village or city. In other words,

war-related factors such as lose of family members, disruption of early childhood education, and lack of interest due to prolonged absence from schools. 
children in migrant households attend schools located far away compared to children in non-migrant households in these two districts. However, in the Batticaloa district, a greater percentage of children in non-migrant households attend schools that are located in other villages/cities. The in-depth interviews revealed that migrant households are in a better position to bear the additional travelling costs due to sending kids to schools away from own village/city. If it is assumed that schools located in remote cities provide better education, one could argue that children in migrant households have access to quality education as their parents finance additional costs.

Walking is the main mode of travelling for a majority of children in both migrant and non-migrant households in the Nuwara Eliya and Batticaloa districts while public transport becomes the main mode of travelling for school children in the Kurunegala district. However, a sizable percentage of children in migrant household travel to school by their household owned vehicles. In the Kurunegala district, around 20-30 per cent of school-going children travel to schools by private school vans. Although the in-depth interviews revealed many cases where children in migrant households travel to school-by-school vans, data in household survey do not show that picture. Instead, it could be seen that

\footnotetext{
${ }^{7}$ Education related to difficulties mainly refer to difficulties in carrying out home-work and preparing for examinations.
}

around 20 per cent of total children in migrant households travel to school by household owned vehicles, mostly by bikes and three-wheels.

\section{Parents Migration and Educational Difficulties}

The household survey collected information related to educational difficulties experienced by schoolgoing children in migrant households. In addition, questions were posed during the in-depth interviews to both school-going children as well as to teachers/principals regarding difficulties faced by school-going children of migrant households. In this context, the focus was mainly on children's difficulties in carrying out homework and preparing for examinations. The household surveybased results are reported in Table 4. Accordingly, children reported difficulties related to education after mother/father migrated ${ }^{7}$. In the Kurunegala district, around 18 per cent of children in migrated households reported difficulties with respect to education even when mother/father or both were in Sri Lanka (before migration) and this number increased to 40 per cent after their father/mother or both migrated (see Table 4). Similarly, in the Nuwara Eliya district, around 7 per cent of children in migrated households reported difficulties with respect to education even when mother/father or both were 
in Sri Lanka (before migration) and this number increased to 29 per cent after their father/mother or both migrated. In the Batticaloa district, around 18 per cent of children in migrated households reported difficulties with respect to education even when mother/father or both were in Sri Lanka (before migration) and this number increased to 54 per cent after their father/mother or both migrated. These results imply that absence of mother/father or both has had some impact on education related activities. The in-depth interviews revealed that children faced several difficulties in carrying out education related activities due to absence of mother/father or both. The main difficulty among them is the absence of support for homework and preparation for examinations.

Table 4: Parent Migration and Educational Difficulties at School

\begin{tabular}{|c|c|c|c|c|}
\hline \multicolumn{5}{|c|}{ Before Parent(s) Migration } \\
\hline & Kurunegala & Nuwara Eliya & Batticaloa & Total \\
\hline Yes & 18.4 & 7.4 & 27.0 & 17.7 \\
\hline No & 81.6 & 92.6 & 73.0 & 82.3 \\
\hline Total & 100.0 & 100.0 & 100.0 & 100.0 \\
\hline \multicolumn{5}{|c|}{ After Parent(s) Migration } \\
\hline & Kurunegala & Nuwara Eliya & Batticaloa & Total \\
\hline Yes & 40.0 & 29.1 & 53.7 & 35.0 \\
\hline No & 60.0 & 70.9 & 46.3 & 65.0 \\
\hline Total & 100.0 & 100.0 & 100.0 & 100.0 \\
\hline
\end{tabular}

Source: Based on household survey

In this regard, it is useful to examine children's perception on parents' attitude towards their education, specifically school performance. Parents' attitude towards children education is one of the key determinants of children's success in education. In most cases, children may perform poorly if they feel that their parents do not care about their school performance. During the in-depth interviews with children, parents, and teachers/principals, it was revealed that some parents pay greater attention to children education by assisting directly and/or sending tuition classes. This behavior is common among migrant households where father is the migrant. Table 6 summarizes household survey results related to how children perceive parents' attitude towards their education before and after the mother, father, or both migrated. In the Kurunegala district, around 1 per cent of children perceived that their parents 'do not care about education' even when the parents were around them (before migration). Now (after migration), around 4 per cent of total children in migrant households perceived that their migrated parent as well as remaining members (mother/father/grandparents) do not care about their education. In the 
Nuwara Eliya district, around 9 per cent of total children felt that their parents 'do not care about education' even before his/her mother/father/both migrated (before migration). Now (after migration), around 17 per cent of total children felt their parents 'do not care education'. On the other hand, in Kurunegala, around 68 per cent of total children responded that their parents are concerned about the educational performance and often kept contact with teachers before parent(s) migrated. However, the percentage of children who still (after migration) feel that their parents do concern education and often keep contact with teachers dropped to 57 indicating that some children increasingly feel isolated. Hence, the main message of the above findings is that a sizable portion of children in migrated households feel that their educational activities were moderately affected due to absence of parents (migrated mother/father/or both). In this regard, lack of physiological support and care may create a barrier for childhood development including learning. During the in-depth interviews, it was revealed that absence of mothers has had greater impact on educational performance of some children, especially kids in kindergarten and less than primary. Moreover, some children do not get cleaned well and cloths are often poorly washed. Most of the occasions, school-going kids are given fast-foods prepared by hotels/restaurants due to absence of their mothers. Lack of proper cleanness and hygiene often causes illnesses among children.

Table 5: Children's Perception on Parents' Attitude toward His/Her Education Parent's Attitude Education (Before Migration)

\begin{tabular}{|c|c|c|c|c|}
\hline & \multicolumn{3}{|c|}{ Nuwara } & \multirow[b]{2}{*}{ Total } \\
\hline & Kurunegala & Eliya & Batticaloa & \\
\hline They do not care at all & 0.7 & 8.8 & 23.0 & 11.2 \\
\hline Only care about examination marks & 8.1 & 20.3 & 17.1 & 15.4 \\
\hline $\begin{array}{l}\text { Concern about my school performance but } \\
\text { never contact with the teachers }\end{array}$ & 21.3 & 27.7 & 15.8 & 21.6 \\
\hline $\begin{array}{l}\text { Concern about my school performance and } \\
\text { often contact with the teachers }\end{array}$ & 68.4 & 39.2 & 38.2 & 47.9 \\
\hline Do not know & 1.5 & 4.1 & 5.9 & 3.9 \\
\hline Total & 100.0 & 100.0 & 100.0 & 100.0 \\
\hline \multicolumn{5}{|c|}{ Parent's Attitude Toward Education (After Migration) } \\
\hline & \multicolumn{3}{|c|}{ Nuwara } & \\
\hline & Kurunegala & Eliya & Batticaloa & Total \\
\hline They do not care at all & 4.4 & 16.9 & 23.0 & 15.1 \\
\hline Only care about examination marks & 5.9 & 22.3 & 15.8 & 14.9 \\
\hline $\begin{array}{l}\text { Concern about my school performance but } \\
\text { never contact with the teachers }\end{array}$ & 27.2 & 31.1 & 18.4 & 25.5 \\
\hline $\begin{array}{l}\text { Concern about my school performance and } \\
\text { often contact with the teachers }\end{array}$ & 56.6 & 27.0 & 34.2 & 38.8 \\
\hline
\end{tabular}




\begin{tabular}{lrrrr} 
Do not know & 5.9 & 2.7 & 8.6 & 5.7 \\
Total & 100.0 & 100.0 & 100.0 & 100.0 \\
\hline
\end{tabular}

Source: Based on household survey

\section{Parental Migration and School Dropout}

School dropout is relatively prominent among children in migrant households compared to non-migrant households in all district. In most cases, children in migrant households tend to leave school after GCE Ordinary Level (O/L). A number of interesting facts relating to school dropouts and poor school attendance emerged during the indepth interviews with children and teachers/principals. Teachers and principals mentioned that poor school attendance is prominent among children in migrant households. Moreover, it is reported that some children in migrant households do not show sufficient interest in education. Due to these reasons, school performance with respect to some children in migrant households is relatively poor resulting in school dropout at national exams such as GCE Ordinary Level. In line with the findings of our in-depth interviews, in the household survey, 'being weak in education' and 'exam failures' have been cited as main reasons for leaving schools by school leavers in migrant households in the Kurunegala and Nuwara Eliya districts while poverty and being weak in education are the two mostly cited reasons for school leaving in the Batticaloa district (see Table 6). Even through there is poor evidence to suggest that mother/father or both migration has had an impact of school drop-out in our household survey, in-depth interview and key informant interviews provided overwhelming evidence to suggest that to a greater extent school dropout among children in migrant household is largely due to the absence of father/mother or both at the household. In-depth interviews also captured some cases of school leaving in all three districts. Lack of attention from the father/guardian often lead to school dropout. It was observed that children in migrant household receive assistance and encouragement for education when they live in an extended family where relatives of the migrant(s) take care of educational activities. In those cases, children in migrant household actually benefit through a number of ways.

Table 6: Reasons for School Leaving

\begin{tabular}{lccccccrr}
\hline & \multicolumn{2}{c}{ Kurunegala } & \multicolumn{2}{c}{ Nuwara Eliya } & \multicolumn{2}{c}{ Batticaloa } & \multicolumn{2}{c}{ Total } \\
\cline { 2 - 8 } Reasons & NM & M & NM & M & NM & M & NM & M \\
\hline Due to long distance & 0.0 & 0.0 & 0.0 & 0.0 & 0.0 & 7.7 & 0.0 & 3.8 \\
Poverty (lack of income) & 0.0 & 0.0 & 0.0 & 0.0 & 42.9 & 38.5 & 25.0 & 19.2 \\
Be weak in education & 0.0 & 20.0 & 0.0 & 50.0 & 42.9 & 23.1 & 25.0 & 30.8
\end{tabular}




\section{Original Article}

\begin{tabular}{lrrrrrrrr} 
Exam failures & 0.0 & 80.0 & 0.0 & 12.5 & 0.0 & 7.7 & 0.0 & 23.1 \\
Lack of support from the & 0.0 & 0.0 & 0.0 & 12.5 & 14.3 & 7.7 & 8.3 & 7.7 \\
family & 100.0 & 0.0 & 0.0 & 0.0 & 0.0 & 15.4 & 16.7 & 7.7 \\
Other & 0.0 & 0.0 & 100.0 & 25.0 & 0.0 & 0.0 & 25.0 & 7.7 \\
Not responded & 100.0 & 100.0 & 100.0 & 100.0 & 100.0 & 100.0 & 100.0 & 100.0 \\
\hline Total & & & & &
\end{tabular}

NM: Non-Migrant; M=Migrant

Source: Based on household survey

The evidence suggests that, among school leavers, children in migrant households have schooled less years compared to those of non-migrant households. Out of the total sample, around 26 per cent of total school leavers have just received less than 10 years of education. Children in migrant households in the Batticaloa and Nuwara Eliya districts drop out at the earlier grades compared to that of the Kurunegala district. There is evidence that elder brother/sisters as well as younger brothers/sisters do not school in some migrant as well as non-migrant households. This number is marginally high in-migrant households compared to non-migrant households. The household questionnaire contained a question to examine school leavers' willingness to school again provided they received a chance. It is found that around 30-40 per cent of school leavers in migrant households in the Kurunegala and Batticaloa districts would like to school again. Similarly, around 31 per cent of school leavers in migrant households in Nuwara Eliya would like to re-school if they receive a chance. As mentioned earlier, most school leavers in migrant households in these two districts drop out at lower grades. Compared to school leavers in migrant households, school leavers in migrant households do not wish to school again.

Impact of Parental Migration on Educational Performance

Even though school attendance related data are collected, the cross-verification with teachers, principals and key informants indicated that the records obtained from school-going kids are less reliable. During the in-depth interviews and key informant discussions, it was found that school attendance among some children in migrant households is relatively poor compared to the children in migrant households. According to teachers, there are a number of factors affecting this situation. Among them, lack of support (in terms of preparing foods, cloths, etc.) and attention (for homework, attending to parent meeting, etc.) have cited as mostly affected factors. Some fathers in migrant households do not attend class-room meetings and their kids find it difficult to face teachers and peers when their parents do not attend important events such as class room meetings. As a consequence, those kids tend to skip days on which those events are held. 
Table 7: Effect of Father/Mother/Both Migration on Children's Education

\begin{tabular}{lrrrr}
\hline & Kurunegala & Nuwara Eliya & Batticaloa & Total \\
\hline Negatively affected & 31.6 & 33.1 & 34.9 & 33.3 \\
Not affected & 68.4 & 54.7 & 65.1 & 62.6 \\
Not responded & 0.0 & 12.2 & 0.0 & 4.1 \\
\hline Total & 100.0 & 100.0 & 100.0 & 100.0 \\
\hline
\end{tabular}

Source: Based on household survey

Household survey asked about schoolgoing children's perception about whether the parent migration affected their educational performance (see Table 7). In this regard, attention was paid on whether their school performance (measured in terms of marks obtained, teachers' appreciation etc.) was affected due to the absence of parents. Accordingly, around twothird of the children believe that their mother/father or both migration has affected their education. This fact was further reaffirmed by the teachers/principals and key informants. It is also interesting to note that over 60 per cent of the children in migrant household maintained that the migration has had no impact on their education. It does not necessarily mean that those students perform better in terms of education.

Key informant discussions as well as in-depth interviews revealed that school-going children in migrant families are often responsible for attending to various house work, partly because either the mother/father or both are absent at the home. Moreover, the children in migrant household more often engage in leisure activities largely due to the absence of supervision from their parents. The household survey data revealed that a significant share of children in migrant households spent time playing with friends, watching television, engaging in economic activities compared to the children in non-migrant households (see Table 8). Around 14 per cent of the children in migrant households engage in economic activities in the Batticaloa district. Lack of attention from parents (due to migration) may be one of the reasons for engaging in activities not related to education. Overall, over 72 per cent of the children in non-migrant households mostly engage in homework compared to 47 per cent of total the children in migrant households. This is a clear indication that children tend to engage in activities not directly relating to education during the post-school time period. Lack of direction and attention of parents could be one of the reasons for pushing the children in migrant households to engage in activities not directly related to education. For instance, 21 per cent of the children in migrant households watch television during after-school time whereas this number is around 12 per cent in nonmigrant households. Moreover, it was found, during in-depth interviews and 
focus group discussions, that the children in migrant households do not listen (or obey) to their guardians, in particular, when they live with grandparents. Similarly, some schoolgoing children in migrant households do have to play the role of a baby sitter when they have younger sisters/brothers. In some cases, children in migrant households engage in house activities as well. For instance, around 8 per cent of the children in migrant households engage in house work (such as washing clothes, collecting fuelwood, cleaning kitchen items etc.) compared to 3 per cent of children in migrant households. Children in mother migrated and both parent migrated households mostly engage in house work (except education related activities). For instance, 72 per cent of the children in total mother migrated households engage in washing cloths while this number is around 60 per cent in father and both parent migrated households. Similarly, 39 per cent of total mother and both parents migrated households engage in cooking whereas this number is around 28 for father migrated households. Around 20 per cent of total children in mother migrated households and 36 per cent of total children in both parent migrated households report that the amount of housework has increased after mother/both parents migrated. Children in father and both parents migrated households often receive chances to meet friends while children in mother migrated households do not receive it. For instance, 35 per cent of children in father migrated households and 39 per cent of both parent migrated households meet friends more often while only 26 per cent of children in mother migrated household receive this chance. Hence, the heavily workload born by children in mother migrated (as well as both migrated) households may have a negative impact on children's educational performance.

Table 8: After School Activities

\begin{tabular}{lrrrrrrrr}
\hline & \multicolumn{9}{c}{ Nuwara } & & & & Total \\
& \multicolumn{1}{c}{ Kurunegala } & Eliya & Batticaloa & NM & M \\
\hline Do my & NM & M & NM & M & NM & M & NM \\
homework/reading/revision & 72.0 & 46.3 & 90.0 & 48.6 & 58.3 & 48.0 & 72.5 & 47.7 \\
Play with some friends & 14.0 & 20.6 & 2.5 & 22.3 & 8.3 & 13.2 & 8.7 & 18.6 \\
Watch TV/Listen music & 14.0 & 27.9 & 7.5 & 23.0 & 14.6 & 13.2 & 12.3 & 21.1 \\
Surf internet & 0.0 & 0.0 & 0.0 & 1.4 & 2.1 & 1.3 & 0.7 & .9 \\
Do housework & 0.0 & 3.7 & 0.0 & 4.1 & 8.3 & 14.5 & 2.9 & 7.6 \\
Engage in an economic activity & 0.0 & 0.0 & 0.0 & 0.7 & 6.3 & 9.2 & 2.2 & 3.4 \\
Other & 0.0 & 1.5 & 0.0 & 0.0 & 2.1 & 0.7 & 0.7 & 0.7 \\
\hline Total & 100.0 & 100.0 & 100.0 & 100.0 & 100.0 & 100.0 & 100.0 & 100.0 \\
\hline
\end{tabular}

Source: Based on household survey 
As an indirect measure of children's educational performance, the household questionnaire asked the children to grade their educational performance (see Table 9). According to their own ranking, children in migrant households tend to perform poorly in education compared to their counterparts in non-migrant households. For instance, around 10 per cent of children feel that they perform poorly whereas only 2 per cent of children in non-migrant households feel they perform poorly in education. It is interesting to note that around 19 per cent of total students in nonmigrant households feel that they do their studies excellently whereas only 8 per cent of total children in migrant households feel in similar way.

Table 9: Students' Feeling on Their Own Educational Performance

\begin{tabular}{lllllllll}
\hline & \multicolumn{2}{l}{ Kurunegala } & \multicolumn{2}{l}{ Nuwara Eliya } & \multicolumn{2}{c}{ Batticaloa } & \multicolumn{3}{c}{ Total } \\
\hline & NM & M & NM & M & NM & M & NM & M \\
\hline Excellent & 4.2 & 3.8 & 25.0 & 5.4 & 29.3 & 13.7 & 18.6 & 7.7 \\
Good & 62.5 & 47.3 & 50.0 & 49.3 & 29.3 & 46.0 & 48.1 & 47.6 \\
Just so do & 33.3 & 43.5 & 25.0 & 31.8 & 34.1 & 25.9 & 31.0 & 33.5 \\
Poor & 0.0 & 5.3 & 0.0 & 11.5 & 7.3 & 12.2 & 2.3 & 9.8 \\
Very poor & 0.0 & 0.0 & 0.0 & 2.0 & 0.0 & 2.2 & 0.0 & 1.4 \\
\hline Total & 100.0 & 100.0 & 100.0 & 100.0 & 100.0 & 100.0 & 100.0 & 100.0 \\
\hline
\end{tabular}

Source: Based on household survey

Household questionnaire as well as indepth interviews focused on obtaining information related to how the students in migrant households feel about their educational performance after their parents migrated. It is important to mention that in some houses, the parents have migrated several times including the recent one. Table 10 reports some data related to the schoolgoing children's perception on their educational performance after the migration. Accordingly, around 16 per cent of total school-going children in migrant households feel that their school performance is worse than before. In the Nuwara Eliya district, this figure stands somewhere around 22 per cent. At the same time, it is important to note that there are around
12 per cent of total school-going children who feel that they actually experienced somewhat better performance after their parents migrated. Similarly, around two-third of children in migrant households feel that their school performance did not change after the migration. Hence, evidence against the hypothesis that education is affected due to parent migration is not overwhelming. It is important to mention that, as discussed elsewhere, some children in migrant households actually perform better than previously due to the support they receive from close relatives as well as due to their admission to tuition classes. Parent(s) migration has made it possible to attend tuition classes which were not possible due to lack of 
financial capacity. It was revealed that, during in-depth interviews and key informant discussions, children living with close relatives actually perform well in education due to the support and the supervision of the extended family members.

Table 10: School Performance Change After Parent(s) Migrated

\begin{tabular}{lllll}
\hline & Kurunegala & Nuwara Eliya & Batticaloa & Total \\
\hline Worse than before & 7.4 & 22.3 & 17.8 & 16.1 \\
No different & 83.8 & 52.0 & 63.2 & 65.8 \\
Better than before & 6.6 & 18.9 & 9.2 & 11.7 \\
Do not know & 2.2 & 6.8 & 9.9 & 6.4 \\
Total & 100.0 & 100.0 & 100.0 & 100.0 \\
\hline
\end{tabular}

Source: Based on household survey

School performance is poorer when the length of the migration is longer. For instance, 18 per cent of children reported that their education performance is worse than before in households where mother/father or both migrated less than 3 years while this number is 24 per cent and 26 per cent for households whether mother/father or both parents have migrated, respectively, 3-5 years and more than 5 years. When rounds of mother migration increases, children educational performance become poorer. For instance, 15 per cent of children in mother migrant households reported that their educational performance is worse than before (when mother is in Sri Lanka) and this figure increased to 20 per cent and 22 per cent for children whose mothers have migrated round 2 and 3 respectively. Education level of migrant mother, father, or both parents do not affect the educational performance of children. This might be partly due to the fact that most migrant parents report low educational performance.

\section{Regression Analysis}

The above analysis shed some light on the impact of parental migration on educational performance of children left-behind. In order to further strengthen the findings, a logistic regression framework, as outlined in the methodology section, is employed in looking at the determinants of students' educational performance. The survey gathered data on children's perception on their educational performance (achievement in test) compared to their peers. The perception is measured using fivecategory Likert Scale, namely Excellent, Good, Average, Poor, and Very poor. Our dependent variable is a binary variable that is constructed using above information. It takes 1 if the perception is average or above and zero otherwise. As per theory and empirical findings, a number of external and internal factors affect students' 
educational performance (Nisar, et. Al., 2017; Betts et. al., 2014; Betts, et. al., 2003). The external factors include household-level factors such as level of income, parents' education levels and occupations, level of siblings' education, quality of school attended, and whether or not students receive extra educational support such as tuition. Internally, factors such as students' commitment and attitude towards educational activities, school attendance, past performance, and biological factors affect the performance. The regression analysis makes use of some explanatory variables focusing more on family environment related aspects such as number of siblings, parent's education levels, after-school activities, and level of engagement with household activities. Some of the variables such as household income was not considered partly due to the fact that the survey was administered among children and their capacity to divulge information on household income remains low. Both migrant and non-migrant households are in same vicinity and socio-economic status are mostly similar. Improvement in income, due to migration, may be captured in the model through the binary variable.

The estimated results are reported in Model (1) through Model (6) in table 11. As expected in theory and in consistence with the empirical findings, amount of time allocated on housework (in terms of number of tasks involved) has a negative impact on educational achievement. The estimated coefficient of housework engagement is negative (-0.109) and significant at the conventional level of significance in model (6). An increase in number of housework implies that children allocate more after-school time as well as time in holidays for non-educational household activities. As a result, time left for studies and leisure becomes limited and, in a competitive learning environment, those students perform poorer compared to the students who engage less in housework. The estimated coefficient of after school activities is positive and statistically significant in model (1) through model (6). In other words, educational performance is better among students who mostly engage in educational activities during the after-school time. Broadly speaking, students could utilize their after-school and holidays time for three purposes, namely for education, leisure, and housework. Students who use time for housework mostly have limited time for education and leisure. Those who engage less in housework could utilize their time for education and leisure. Students both in migrant and non-migrant households could achieve better educational outcomes provided students use more time on educational activities.

The estimated results suggest that the household head's education level has no effect on children's educational outcomes. The existing literature clearly provides evidence, both theory 
and empirics, that parent education level makes a sizable influence of children's educational achievement (Nisar, et. Al., 2017; Betts et. al., 2014; Betts, et. al., 2003). The absence of evidence may be due to few factors, namely (a) less variation in household heads' education levels and (b) relatively low level of education among household heads both in migrant and non-migrant household heads.

The estimated coefficient of migration status (migrant household=1, otherwise $=0$ ) is not statistically significant in model (3) through model (6). The migration status variable captures both positive effects, such as more financial resources for education, as well as negative effects, such as lack of close parental supervision and support, on migrant household children's educational achievement compared to children in non-migrant households.

The result suggests that the net effect is not statistically meaningful. However, descriptive data analysis showed that children in mother migrant households face less conducive environment for studies compared to that of the other households. Hence, the models 4 through 6 were introduced a dummy variable that takes 1 for mother migrant households and otherwise zero. The estimated coefficient of this dummy is negative (-0.839) and statically significant at 1 per cent level of significance in model (3) through model (6). Mothers influence children education through a number of channels. According to Baker and Stevenson (1986), mothers influence children's educational achievements by encouraging children to engage in homework and school attendance, by contacting teachers and taking appropriate actions to improve performance, and by selecting suitable additional educational resources, such as tuition for difficult subjects. The absence of mothers at home, hence, could negatively affect children's educational performance. Our findings are in consistence with previous literature on the effect of mother migration of educational performance of children left behind (Dissanayake, et. al., 2014). For a sample of school children in the Gampha district, the authors found that school-level examination marks are lowers for children whose mothers are in abroad compared to other children. Perera and Rathnayaka (2013) and Save the Children (2006) found that children of absent mother are also more likely to drop out of schools. 
Journal of Social Sciences and Humanities Review (JSSHR)

Vol. 5, No. 2 (98-128)

(C) Author(s) 2020

Original Article

ISSN: 2279-3933

Table 11: Impact of Parental Migration on Children's Education

\begin{tabular}{|c|c|c|c|c|c|c|}
\hline & Model (1) & Model (2) & Model (3) & Model (4) & Model (5) & Model (6) \\
\hline \multirow[t]{2}{*}{ Constant } & $0.342 * *$ & -0.204 & -0.089 & -0.164 & -0.149 & -0.097 \\
\hline & $(0.179)$ & $(0.347)$ & $(0.411)$ & $(0.417)$ & $(0.427)$ & $(0.430)$ \\
\hline \multirow[t]{2}{*}{ Housework engagement (number of tasks involved) } & $-0.136^{* * *}$ & $-0.145^{* * *}$ & $-0.141 * * *$ & $-0.126 * *$ & $-0.117 * *$ & $-0.109^{* *}$ \\
\hline & $(0.043)$ & $(0.045)$ & $(0.046)$ & $(0.047)$ & $(0.048)$ & $(0.048)$ \\
\hline \multirow[t]{2}{*}{ After school activities ( $1=$ engaged mostly in education activities; $0=$ otherwise $)$} & $0.708 * * *$ & $0.671 * * *$ & $0.646 * * *$ & $0.600 * * *$ & $0.612 * * *$ & $0.600 * * *$ \\
\hline & $(0.178)$ & $(0.183)$ & $(0.189)$ & $(0.192)$ & $(0.195)$ & $(0.196)$ \\
\hline \multirow[t]{2}{*}{ Number of adult siblings } & & $0.168 * *$ & $0.164 * *$ & $0.171 * *$ & $0.188^{* *}$ & $0.174 * *$ \\
\hline & & $(0.083)$ & $(0.08) 3$ & $(0.084)$ & $(0.086)$ & $(0.086)$ \\
\hline \multirow[t]{2}{*}{ Education of head of household ( $1=$ secondary and above, $0=$ less than secondary) } & & 0.091 & 0.087 & 0.104 & 0.049 & 0.042 \\
\hline & & $(0.076)$ & $(0.076)$ & $(0.078)$ & $(0.079)$ & $(0.088)$ \\
\hline \multirow[t]{2}{*}{ Migration status ( $1=$ migrant household, $0=$ non-migrant household) } & & & -0.119 & 0.317 & 0.243 & 0.243 \\
\hline & & & $(0.230)$ & $(0.263)$ & $(0.268)$ & $(0.270)$ \\
\hline \multirow[t]{2}{*}{ Mother migrant household ( $1=$ mother migrant household, $0=$ otherwise $)$} & & & & $-0.772 * * *$ & $-0.773 * * *$ & $-0.839 * * *$ \\
\hline & & & & $(0.215)$ & $(0.219)$ & $(0.236)$ \\
\hline \multirow[t]{2}{*}{ Distance to school (in KM) } & & & & & $0.082 * *$ & $0.085^{* *}$ \\
\hline & & & & & $(0.039)$ & $(0.039)$ \\
\hline District effects & & & & & & No \\
\hline Log likelihood value & -359.68 & -341.027 & $-340 . .89$ & -334.30 & -321.46 & -322.08 \\
\hline No of observations & 546 & 520 & 520 & 520 & 509 & 509 \\
\hline Pseudo $\mathrm{R}^{2}$ & 0.033 & 0.038 & 0.039 & 0.057 & 0.070 & 0.070 \\
\hline
\end{tabular}

Note: Standard errors are reported in parentheses while $* *$ and $* * *$ indicate that the estimated coefficients are statistically significant at 5 per cent and 1 per cent respectively. 
Impact of Parental Migration on Protection

The impact of mother's migration on left-behind children's protection was primarily assessed using data gathered through key informant and in- In-depth interviews. In addition, some relevant information was collected through household questionnaire as well. Key informant and in-depth interviews revealed that a sizable share of children belong to migrant households live with people other than their parents. Table 12 reports data, extracted from the household survey, on with whom children in migrant households live after their parent(s) migrated. Accordingly, around 30 per cent of children live with mother (where father has migrated) or father (where mother has migrated). Another 24 per cent of children in migrant households live with grandparents (either mother or father or both have migrated). Around 13 per cent of children in migrant households live with father's or mother's relatives while around 3 per cent live with the others ${ }^{8}$. It is also noticeable that nearly half of the children in migrant households in Batticaloa district live with people other than their parents. Key informant interviews revealed cases where children of migrant households were subject to various abuses when living with outsiders.

Table 12: Living Environment (with whom live)

\begin{tabular}{lllll}
\hline Living with & Kurunegala & Nuwara Eliya & Batticaloa & Total \\
\hline Mother & 33.8 & 14.9 & 39.5 & 29.4 \\
Father & 30.9 & 50.7 & 9.9 & 30.3 \\
Grand Parents & 24.3 & 23 & 25.7 & 24.3 \\
Relatives of Mother/Father & 9.6 & 11.5 & 17.8 & 13.1 \\
Neighbors & 0 & 0 & 4.6 & 1.6 \\
Child probation center & 0 & 0 & 0.7 & 0.2 \\
Others & 1.5 & 0 & 2 & 1.1 \\
\hline Total & 100 & 100 & 100 & 100 \\
\hline
\end{tabular}

Source: Based on household survey

Moreover, it was revealed that there is a great threat on children protection when they live with father, in particular for young females, if father is not well educated and if he is a regular alcohol taker. During the in-depth interviews and key informant discussions, a

\footnotetext{
${ }^{8}$ This consists of 1.6 per cent at neighbors' places, 0.2 per cent at probationary centers, and 1.1 per cent at other people' places.
}

number of cases were highlighted that young female were subject to abuse by father's close associate or visitors due to lack of father's attention. Similarly, it was revealed that protection under mother care is always not guaranteed as well. Key informant and in-depth 
interviews revealed that children in migrant households often change their place of living thereby exposing to different people and context. Frequent changes into place of living happen due to a number of factors such as (a) disagreement over ownership, (b) alleged abuses, (b) separation of parents, and (c) not receiving expected financial benefits. Household survey collected data on the number of places children of migrant households have lived other than the present place during the last year. Accordingly, around 15 per cent of children in migrant households have lived more than 3 other places while around 14 per cent of children have lived in more than 4 places other than the present places. This reflects that parent migration more often changes children's living environment thereby exposing them to various people and contexts. Along with this change, children tend to meet with new friends and people. In most cases, children get admitted to new schools in line with the shift of their living places. Adopting into these new environments may associate with heavy mental and psychological pain thereby having long-term impact on early childhood development. When children were ejected from their familiar environment and friends, they need time to make new friends. With respect to protection, the change in living places poses a greater risk.

Key informant and in-depth interviews also highlighted that children in migrant household engage in various house-work as well as outside home activities which could affect their physical and mental wellbeing and protection. In particular, those children are requested to engage in activities that may pose threats to their physical well-being (see Table 14). It is noticeable that children in mother migrant households are more likely to engage in such activities compared to that of the father migrant households. Moreover, if both father and mother are abroad, children of such households have a higher probability to engage in house and out-side the house activities. According to key informants, this is almost similar to a situation of using child labour. In-depth interviews also highlighted such situations where relatives of mother migrant households as well as the father want children to engage in some out-side the house work. In contrast, children's engagement in similar activities are relatively lower in non-migrant households.

Table 14: What House Work You Involve

\begin{tabular}{llllll}
\hline & & \multicolumn{3}{c}{ Migrated member } & \\
\cline { 3 - 5 } Type of activity & Yes/No & Mother & Father & Both \\
\hline \multirow{3}{*}{ Attend the ill } & Yes & 29.9 & 13.6 & 35.5 \\
& No & 70.1 & 86.4 & 64.5 \\
& Total & 100.0 & 100.0 & 100.0 \\
\hline
\end{tabular}




\begin{tabular}{lllll} 
& Yes & 18.3 & 7.1 & 25.8 \\
Hew/cut/chop & No & 81.7 & 92.9 & 74.2 \\
& Total & 100.0 & 100.0 & 100.0 \\
\hline \multirow{3}{*}{ Plough } & Yes & 12.0 & 9.1 & 22.6 \\
& No & 88.0 & 90.9 & 77.4 \\
& Total & 100.0 & 100.0 & 100.0 \\
\hline \multirow{2}{*}{ Weed } & Yes & 19.1 & 13.6 & 22.6 \\
& No & 80.9 & 86.4 & 77.4 \\
\hline
\end{tabular}

Source: Based on household survey

Key informant and in-depth interviews revealed that there are four major impact areas that pose threats to children in migrant households and such threats are severe for children whose mother or both parents are in abroad. First, children face higher risks with the use of alcohol and tobacco and are subject to sexual harassments. Second, children in mother migrant households are more likely to feel depression and isolation. As a result, they tend to seek outsiders' love and assistance which often pose greater risks in abuses. Third, it could be witnessed that children in migrant households to become more aggressive and rebellious compared to that of the non-migrant households. Both key informant and in-depth interviews found the problem of children becoming aggressive or rebellious as a consequence of migration that appeared to be quite common among migrant households. Aggression appeared to be particularly common among boys (who often did not respect

\footnotetext{
${ }^{9}$ This was more common with girls than boys and particularly pronounced for children in households lacking family support and guardian remains weak. Female respondents aged 15-18 appeared to be the
}

their mother's or guardian authority). The research showed that there was no explicit stigma associated with being the children of migrants, probably because the phenomenon is so widespread in the country. However, there were several reports of abandoned children being teased because their father had married another woman or vice-versa and 'forgotten' about them. Finally, it is also revealed that children in mother migrant households are more likely to subject to bullying at schools and the society. Evidence from the key informant interviews clearly showed that children left behind had a tendency to become withdrawn, sad and depressed ${ }^{9}$. A number of cases were highlighted by key informants where children from migrant families are more likely to commit crime and be victims of abuse. In some occasions, crimes are not referred to legal entities since such crimes are committed by a close-relatives or family members. In general, children in households with

most affected by sadness and depression. Younger children across the three categories appear to be less affected, while older children - especially those 1518 - show higher levels of sadness and depression. 


\section{Original Article}

weak guardians and weak family support mostly engage in crimes and be victims of abuse.

A number of negative effects due to migration emerged during the in-depth interviews, focus group discussions as well as from the survey data. First, it is found that family separation and/or disintegration happens due to various mistrust between male and female partners during and/or post migration period. The family separation occurs due to misbehavior of the partner who stay with kids and/or who is in abroad. Family disintegration has made huge impact on children education and protection (well-being). Second, even without family dis-integration, mother migration has huge negative impact on the overall development of a child ranging from education, health, behavior, cleanness, and development. Third, lack of parental guidance and impacts on children's aggressiveness and depression could be witnessed.

Key informant and in-depth interviews revealed that, by and large, one of the most important impacts of a parent's migration on the children left behind is on psycho-social well-being and protection. Especially in households where family support and guardian remain weak, the social costs of migration were found to be high, due to family disintegration, lack of support from relatives, and lack of parental care. Table 15 summarizes the level of impact on children's protection on the basis of who have migrated and living environment along with the maturity of the children left behind. The discussions revealed that it is difficult to argue under whose care children face greater risks. Nevertheless, living with fathers, grandparents, relatives, and neighbors substantially increases the vulnerability to be subjected to various abuses. In most cases, the level of risk depends on the context under which children in migrant household live. It was found that the extended family environment, educated mother/father and better relationship between mother/father and relatives certainly provide better protection for children in migrant households. Further, it is also found that maturity of the left-behind children also determines the level of impact on education and protection. 
Journal of Social Sciences and Humanities Review (JSSHR)

Vol. 5, No. $2(98-128)$

(C) Author(s) 2020

Original Article

ISSN: 2279-3933

Table 15: Impact of Mother Migration on Children Education and Protection

\begin{tabular}{|c|c|c|c|c|c|c|c|c|}
\hline \multirow[b]{2}{*}{$\begin{array}{l}\text { Who migrate/Living } \\
\text { environment }\end{array}$} & \multicolumn{8}{|c|}{ Living Environment and Maturity of Left-Behind Children } \\
\hline & $\begin{array}{l}\text { Guardian } \\
\text { capacity } \\
\text { strong, } \\
\text { Family } \\
\text { support } \\
\text { strong, } \\
\text { teenage }\end{array}$ & $\begin{array}{l}\text { Guardian } \\
\text { capacity } \\
\text { strong, } \\
\text { Family } \\
\text { support } \\
\text { strong, less } \\
\text { than teenage } \\
(<13 y r s) \\
\end{array}$ & $\begin{array}{l}\text { Guardian } \\
\text { capacity } \\
\text { weak, } \\
\text { Family } \\
\text { support } \\
\text { strong, } \\
\text { teenage }\end{array}$ & $\begin{array}{l}\text { Guardian } \\
\text { capacity } \\
\text { weak, Family } \\
\text { support } \\
\text { strong, less } \\
\text { than teenage } \\
\text { (<13yrs) }\end{array}$ & $\begin{array}{l}\text { Guardian } \\
\text { capacity } \\
\text { strong, } \\
\text { Family } \\
\text { support } \\
\text { weak, } \\
\text { teenage }\end{array}$ & $\begin{array}{l}\text { Guardian } \\
\text { capacity } \\
\text { strong, } \\
\text { Family } \\
\text { support } \\
\text { weak, less } \\
\text { than teenage } \\
(<13 y r s) \\
\end{array}$ & $\begin{array}{l}\text { Guardian } \\
\text { capacity weak, } \\
\text { Family } \\
\text { support weak, } \\
\text { teenage }\end{array}$ & $\begin{array}{l}\text { Guardian } \\
\text { capacity weak, } \\
\text { Family } \\
\text { support weak, } \\
\text { less than } \\
\text { teenage child } \\
(<13 \text { yrs })\end{array}$ \\
\hline Mother & No impact & Low impact & Low impact & $\begin{array}{l}\text { Medium } \\
\text { impact }\end{array}$ & $\begin{array}{l}\text { Medium } \\
\text { impact }\end{array}$ & High risk & High impact & $\begin{array}{ll}\text { Very } & \text { high } \\
\text { impact } & \\
\end{array}$ \\
\hline Father & No impact & No impact & Low impact & $\begin{array}{l}\text { Medium } \\
\text { impact }\end{array}$ & $\begin{array}{l}\text { Medium } \\
\text { impact }\end{array}$ & $\begin{array}{l}\text { Medium } \\
\text { impact }\end{array}$ & High impact & $\begin{array}{l}\text { Very high } \\
\text { impact }\end{array}$ \\
\hline Both parents & No impact & Low impact & Medium risk & High impact & High impact & High impact & $\begin{array}{l}\text { Very high } \\
\text { impact }\end{array}$ & $\begin{array}{ll}\text { Very } & \text { high } \\
\text { impact } & \end{array}$ \\
\hline
\end{tabular}

Source: Based on household survey, Key Informant and In-depth Interviews

Note:

\begin{tabular}{lll}
\hline Family support & strong & $\begin{array}{l}\text { Living in an extended family and/or relatives living in the neighborhood and tightly } \\
\text { connected with relatives } \\
\text { Nuclear family and/or relatives living far away from the home and loosely } \\
\text { connected with relatives }\end{array}$ \\
\hline Guardian capacity & Strong & $\begin{array}{l}\text { Educated and/or responsible (grandparent not too old) and better relationship } \\
\text { maintained at the family } \\
\text { Less educated and/or irresponsible (grandparent too old) and weaker relationship } \\
\text { maintained at the family }\end{array}$ \\
\hline Children & $\begin{array}{l}\text { Less than teenage } \\
\text { Teenage }\end{array}$ & $\begin{array}{l}\text { Not matured (assumed) } \\
\text { Matured (assumed) }\end{array}$ \\
\hline
\end{tabular}


CONCLUSION

International labour migration has been one of the key sources of employment generation and foreign exchange earnings for Sri Lanka since early 1980s. Annually, over 200 hundred thousand people, both men and women, migrate to a number of countries, mainly to the Middle East, for employment. During the first few decades, female labour migration dominated labour migration flow, however, in recent years, the share of female migrants declined owing to number of reasons. For instance, one of them is the new restriction imposed by the government. Similarly, in recent years, the share of skilled migration has gradually picked up though unskilled migration continued to dominate the migration flow. More importantly, a sizable share of the total migrants fall into the 25-44 age group and their migration may have implications on education and protection of children left behind.

This study aimed at examining the impact of parental migration on children left behind, both on education and protection. After considering the size of the migration flow and ethnic composition, a sample of households, covering both migrant and nonmigrant households, was selected from three administrative districts in Sri Lanka. Household questionnaire, key informant interviews and in-depth interviews were conducted in collecting relevant data for the study. Both descriptive and regression analyses were employed in data analysis and results obtained from above techniques were further enriched by in-cooperating insights from key informant interviews and indepth interviews. A number of pushing and pulling factors have influenced for migration decisions in households in surveying districts: Kurunegala, Nuwara Eliya, and Batticaloa. Among them, economic and social issues are prominent. Poverty and unemployment have played a central role in pushing household members in poor socio-economic background to take up jobs in foreign countries. More importantly, it was revealed that a number of social (or domestic) issues such as domestic violence, family separation, abandoning, and death of the household head have influenced household members to migrate.

Insights from the descriptive analysis, key informant interviews, and indepth interviews highlighted some suggestive evidence that children in migrant households face difficulties with their school attendance and performance compared to children in non-migrant households. In particular, school drop-outs were higher among children whose either parent or both were in abroad. Moreover, children in migrant households were overloaded with housework, including child caring, thereby having limited time for studies. A sizable share of children, in migrant households, was of the opinion that their educational performance was affected due to 
parental migration. These negatives were much clearer among children whose mothers were in abroad. In contrast, suggestive evidence indicated that some children in migrant household receive extra educational support, in terms of tuition, and attend schools located in major cities due to additional financial resources in the form for remittances received by migrant households. Aiming at strengthening above findings, this study employed a logistic regression framework in examining the effect of migration of educational performance where our dependent variable was selfassessment on performance at schoollevel test. A number of explanatory variables were introduced in order to control for household level factors affecting educational performance. Our results clearly indicated that migration status has no effect on educational performance. Nevertheless, we found strong statistical evidence to suggest that educational performance is lower among children whose mother has migrated. In other words, probability is higher that children in mother migrant households perform poorly at test conducted at school-levels. Mothers involve in a number of ways to improve children's educational achievement and their absence at home negatively affects children educational performance.

Our findings suggest that the impact of parental migration on protection of children left-behind largely remains negative. In other words, parental migration may endanger the children's physical and physiological well-being. However, the size of the impact is determined by few factors, namely who have migrated, maturity of the children left-behind, and guardian capacity along with family support. It was observed that impact on protection is relatively little for matured children who are looked after by a capable mother/father who also receives a greater support from relatives. Nevertheless, children's protection is severely under risk when mother/father left their children with either less capable mother/father who receives inadequate/poor support from relatives. In particular, small children in mother migrant households face greater risks irrespective of father's capacities and support received by him from his relatives.

The survey and in-depth interviews found that most household members (those who are at the home at present) described overall impact of migration, in general, as neutral or negative. There were only few cases where migration has led to uplift the socio-economic condition in a sustainable manner. It was reasonably visible that, despite the benefit of additional income, a significant number of migrant households appeared to be doomed about the choice their loved one made to migrate. Nevertheless, it was found that repeated migration has taken place 
leading to a 'chain of migration; horizontally as well as vertically.

\section{References}

Adams R.H. and A. Cuecuecha (2013). The Impact of Remittances on Investment and Poverty in Ghana. World Development, 50, 24-40.

Alcaraz C., Chiquiar D. and A. Salcedo (2012). Remittances, Schooling, and Child Labour in Mexico. Journal of Development Economics, 97(1), 156-165.

Antman, F. M. (2013). The Impact of Migration on Family Left Behind (ch. 16). In A. F. Constant and K. F. Zimmermann (eds.) International Handbook on the Economics of Migration. UK: Edward Elgar.

Baker, D. P. and D.L. Stevenson (1986). Mothers' Strategies for Children's School Achievement: Managing the Transition to High School. Sociology of Education, 59(3), 156-66.

Betts, J. R., Zau, A. C., and L.A. Rice (2003). Determinants of Student Achievement: New Evidence from from San Diego. San Francisco: Public Policy Institute of California.

Brayant, J. (2008). Children and International Migration. In International Organization for Migration (Eds.), Situation Report on International Migration in East and South-East Asia. pp. 177-194. Bangkok: Regional Office for Southeast Asia.

Bronfenbrenner, U. (1986). Ecology of the family as a context for human development: Research perspectives. Developmental psychology 22(6), 723.

Chang, H., Dong, X., and F. MacPhail (2011). Labor migration and time use patterns of the left-behind children and elderly in rural China. World Development, 39 (12), 2199-2210.

Corsaro, W. A. (1997). The Sociology of Childhood. Pine Forge Press, Thousand Oaks, CA.

Cox Edwards, A. and M. Ureta (2003). International Migration, Remittances, and Schooling: Evidence from El
Salvador. Journal of Development Economics, 72(2), 429- 461.

Delprato, D. and B.D. Midgley (2002). Some Fundamentals of B.F. Skinner's Behaviorism. American Psychologist, 47(11), 1507-1520.

Dustmann, C. and A. Glitz (2011). Migration and Education. In Handbook of the Economics of Education, 4, 327-439.

Gamburd, M.R. (2008). Milk Teeth and Jet Planes: Kin Relations in Families of Sri Lanka's Transnational Domestic Servants. City and Society, 20(1), 5-34.

George, H. W. and L. A. Edwards (1989). Parental attitudes toward child rearing: Instruments, issues, and implications. Psychological Bulletin, 106(1), 45-67.

Hettige, S. T. (1999). Social impact of the migration of female workers to the Middle East. A report submitted to the Presidential Secretariat, 18 January, 1999.

James, A. C. Jenks, and A. Prout (1998). Theorizing childhood. Cambridge: Polity Press.

Jampaklay, A. (2006). Parental Absence and Children's School Enrolment: Evidence from a Longitudinal Study in Kanchanaburi, Thailand. Asian Population Studies, 1(2), 69-92.

Lakshman, R. Perera S. and Sangasumana (2015). The children left behind by international migrants from Sri Lanka: victims or beneficiaries of globalization. In G. Dona and A. Veale (Eds), Children, migration \& globalization. New York: Macmillan Palgrave.

Mackie, G. (2002). Functionalist Socialization, Family and Character. Analyse \& Kritik, 24, 40-59.

McKenzie, David; Rapoport, Hillel (2006). Can Migration Reduce Educational Attainment? Evidence from Mexico. Policy Research Working Paper; No. 3952. World Bank, Washington, DC.

Nisar, N., Mahmood, M.K., \& Dogar, A.H. (2017). Determinants of Students' Academic Achievement at Secondary School Level. Bulletin of Education and Research, 39(1), 145-158. 


\section{Original Article}

Perera S. and Jampaklay A. (2014). International migration and children left behind: Impacts on children's school enrolment in Sri Lanka. Sri Lanka Journal of Population Studies, 12-13, 81-100.

Perera, N. and M. Rathnayaka (2013). Sri Lanka's Missing Mothers. Colombo: Save the Children Sri Lanka.

Save The Children Sri Lanka, (2006). Left behind, left out: The impact on children and families of mother migrating for work abroad. Colombo: Save the Children.

Thorne, B. (1987). Re-visioning women and social change: Where are the children? Gender \& Society, 1(1), 85-109.

United Nations Department of Economic and Social Affairs (2019). International Migration 2019. Department of Economic and Social Affairs, New York: United Nations

Wong, T. et al., (2003). 'Migration and the 'Asian' family in a Globalizing world: a selective review. In Wong, T. ET AL (eds.), Researching Migration and the Family. Singapore: Asian Meta Centre.

Vygotsky, L. S. (2004). Imagination and creativity in childhood. Journal of Russian \& East European Psychology, 42(1), 7-97.

Yang, D. (2008). International Migration, Remittances and Household Investment Evidence from Philippine Migrants. Economic Journal, 118(528), 591-630. 